\title{
SECONDARY NURSING SCHOOL STUDENTS PERCEPTION REGARDING CLINICAL LEARNING ENVIRONMENT AND CLINICAL SUPERVISION IN PORT SAID CITYQ
}

\author{
Mona MostafaShazly ${ }^{1}$,Noura El Gharib Mohamed Eldiasty ${ }^{2}$, \\ ShadiaAbdelhadyAbdelhady Ibrahim $^{3}$ \\ Professor of Nursing Administration-Faculty of Nursing -Ain shams University ${ }^{1}$,Lecturer \\ of Nursing Administration - Faculty of Nursing- Port Said University ${ }^{2}$, \\ B.Sc. Nursing- Port Said University ${ }^{3 .}$
}

\begin{abstract}
Background:The clinical learning environment refers to the learning placement that provides opportunities to integrate theory into practice, build clinical decision-making abilities, and develop a professional identity.Aim: to assess the perception of secondary nursing school students regarding their clinical learning environment and clinical supervision in Port Said City.Subjects and Method: A descriptive correlational research designwas used for the current study in three secondary nursing schools at Port- Said city. The study subjects will include 360 femalestudents.Two tools were used for data collection; Clinical learning environment inventory actual and expected form(CLEI), and clinical supervision questionnaire(CSQ).Results:The current study revealed that the majority of nursing students reported that there was low level of actual clinical learning environment (66.47\%), andthe majority of nurse students had a high level of expected clinical learning environment $(76.4 \%)$, also more than half of nurse students had a moderate level of clinical supervision (56.9\%).Conclusion:It was evidenced that there was a significant difference between actual and expected clinical environments. Also the results suggested significant relationship between clinical learning environment and clinical supervision. Recommendations:The main recommendations are suggested, considering students' expectations of clinical teaching environment and decreasingthe gap between the actual and expectedclinical environments is necessary. In addition,continuous studies on clinical teaching environment evaluation and their results, and to assess clinical instructors' and clinical staff opinions about the clinical teaching environment are recommended.
\end{abstract}

Keywords:Clinical Learning Environment, Nursing students and Clinical Supervision. 


\section{INTRODUCTION}

Nursing education is closely related to theoretical and clinical teaching. In this regard, clinical trials of nursing students are an important component of the nursing profession as well as clinical teaching, which is the cornerstone of nursing education (Skaalvik, Normann\&Henriksen, 2011). In clinical placement, the student learns how to apply nursing knowledge, nursing skills, patient communication and professionalization and prepare themselves for future workplace practice. Clinical placements throughout nursing history play a key role in the learning process of nursing students. In addition, nursing students may believe that the clinical environment is the most influential educational component for acquiring knowledge and nursing skills (Berntsen\&Bjørk, 2010).

The clinical learning environment broadly refers to the different physical locations, contexts and cultures in which students learn. In adult learning contexts, students' satisfaction with their learning experience is strongly influenced by the level of student achievement (john \&wilson, 2012). In order to provide an optimal learning environment, educational service providers should ideally understand students' perceptions of their learning experiences in a given environment, thereby enabling analysis of existing structures and planning for meaningful change to enhance learning(Shahi, Bakhshi\& Hassan, 2015).

Clinical experience is still the basis for practice disciplines, such as nursing (Dutile, Wright \&Beauchesne, 2011). The supervision of clinical practice, as part of the educational preparation of nursing registration, is therefore a major consideration of the nursing program (Henderson \& Tyler, 2011). The results of the clinical capacity of nursing students depend heavily on the quality of clinical experience received in the clinical environment. The relationship between the student and clinical supervisor is also very important. The role of clinical supervisor in the clinical experience of nursing students is mainly to guide the nursing student to become the best nursing professional practitioner.

Clinical supervision is the supervision - either directly or indirectly - by the clinical supervisor of the professional procedures and / or the processes carried out by the student or group of students within a clinical placement for the purpose of counseling and providing feedback and assessment of personal, professional and educational 
development in the context of each student's experience Providing a safe, appropriate and high-quality (health workforce for patients in Australia, 2011).

Clinical supervision by clinical supervisors is an integral part of the nursing education process during which clinical accompaniment occurs. Effective and efficient clinical accompaniment can be considered as a means to achieve the goal of integrating theory and practice into nursing education (Beukes\& Nolte, 2013). According to KaphagawaniandUseh (2013) emphasize that learning in clinical practice is an important component of nursing education, considering that nursing is a practice based on practice, which means that nursing is a care profession based on expert knowledge and skills.

\section{Significance of the Study}

The perceptions and experiences of the students regarding clinical supervision provided information from the student's viewpoint, this information could assist nursing school of education to improve the system of clinical supervision (GabiebaDonough,Mariana $\mathrm{M}$ Van Der Heever\& E Stellenberg, 2014). Hence, this study aims to assess the perception of secondary nursing school students regarding their actual and expected clinical learning environment and clinical supervision.

The clinical learning environment is a complex social entity that influences student learning outcomes in the clinical setting, any difference between actual and expected clinical environment will decrease nursing students' interest in clinical environments and has a negative correlation with their clinical performance (BigdeliSh et al, 2015).

\section{AIM OF THE STUDY :}

This study aims to assess the perception of secondary nursing school students regarding their clinical learning environment and clinical supervision in Port Said City.

\section{Objectives:}

1. Assess nursing student's perception of their expected and actual clinical learning environment.

2. Assess nursing student's perception of their clinical supervision. 
3. Find out the relation between clinical learning environment and clinical supervision.

\section{Research Question:}

To achieve the purpose of this study the following questions will be answered:

1. What are the nursing students' perceptions regarding their actually and expected clinical learning environment?

2. What are the nursing students" perceptions regarding their clinical supervision?

3. Is there a relation between clinical learning environment and clinical supervision?

\section{SUBJECTS AND METHOD:}

\section{Research design:}

A descriptive correlational research design was used for the current study.

\section{Study setting:}

The study will be carried out in three secondary nursing schools at Port- Said city namely: Port Fouad secondary school of nursing, El Nasr secondary school of nursing, El Amery secondary school of nursing and the clinical area where students training are (Port Fouad, El Amery, El Nasr, ElZohoor, obstetric specialized Hospital and Al Arab Center).

\section{Study subjects:}

The study will include all nursing students in three academic year of the above mentioned setting, the total number of all students participated in the study in the three Schools were 360 female students, which distributed (120 students) in every school.

\section{TOOLS OF DATA COLLECTION:}

Two tools were used to collect data for this study.

\section{TOOL I: Clinical Learning Environment Inventory (CLEI)}

This tool was used to assessclinical learning environment perception among nursing school students. It was developed by CHAN (2001). It is consisted of two parts: 
Part1: Includes questions about personalcharacteristics of nursing studentsincluding;student name, school name, age, clinical area name, educational year, and number of teachers interviewed with students in the ward.

Part 2: It consisted of two versions of the CLEI, an actual form and expected form, and every formconsisted of 42 itemsgrouped under sex dimensions with seven items per each dimension, Personalization(from one to seven),Student satisfaction(from eight to14),involvement(from 15to21) and Individualization(from 22 to 28), Task orientation(from 29to35), Innovation (from 36to 42). The questionnaires were given to the students twice: Expected form before distribution for clinical area (hospital), and the actual form at the end of training to students. This tool was translated into Arabic and retranslated into English by the researcher and a language expert to ensure the accuracy of the translation.

\section{Scoring System of Clinical Learning Environment Inventory:}

Regarding Clinical Learning Environment Inventory (CLEI) responses were measured along the five-point Likert Scale ranging from strongly agree $=(5)$ to strongly disagree $=(1)$. Items were scored 5, 4, 3, 2, and 1, for the responses "strongly agree", "agree", "neutral", “disagree", and "strongly disagree" respectively; and each invalid response scored 3, whilst negative statements were scored in the reverse manner (item no: $6,7,9$, and 32). The scores of the items were summed-up for each item and the total score was divided by the number of the items, giving a mean score. This score was converted into a per cent score, means and standard deviations were computed. Strongly disagree/disagree, and agree/strongly agree categories are combined to give percentage respondents who agree, are neutral or disagree. The score greater than or equal to $60 \%$ indicates high perception of CLE, while a score of less than $60 \%$ indicates low perception of CLE among nurse students.

\section{TOOLII : Clinical Supervision Questionnaire(CSQ).}

This tool was used to assessclinical supervision perception among nursing students. It was developed by polite and beck (2008). It consisted of 25 items grouped under four dimensions,as the following; Supervisor relationship: consisted ofeight items.Communication /feedback: consisted ofseven items.Leadership style of ward manager: consisted offour items.Learning support assistance: consisted ofsix 
items.This tool was translated into Arabic and retranslated into English by the researcher and a language expert to ensure the accuracy of the translation.

\section{Scoring System of Clinical Supervision Questionnaire:}

Regarding Clinical supervision responses were measured along the five-point Likert Scale ranging from strongly agree $=(5)$ to strongly disagree $=(1)$. Items were scored 5 , 4, 3, 2, and 1, for the responses "strongly agree", "agree", "neutral", "disagree", and "strongly disagree" respectively; and each invalid response scored 3, whilst negative statements were scored in the reverse manner (item no: 24). The scores of the items were summed-up for each item and the total score was divided by the number of the items, giving a mean score. This score was converted into a per cent score, means and standard deviations were computed. Strongly disagree/disagree, and agree/strongly agree categories are combined to give percentage respondents who agree, are neutral or disagree. Total score of the questionnaire classified to three levels first is low (below $50 \%$ ), second level moderate ranged from (50\% to 75\%), and third level is high if the scoring is above $(75 \%)$.

\section{Validity of the tools:}

It was ascertained by a panel of five nursing experts: one professor of nursing administration department (Ain Shams University), one professor of nursing administration department (Mansoura University), one assistant professors from nursing administration department(Port said University) and two assistant professors from Nursing Administration department (Mansoura University). They were requested to express their opinions and comments on the translated tools. The tools were modified according to jury opinions such as clarify some statements, and retranslation of certain words. This phase was carried out in a period of six weeks.

\section{Reliability:}

Cronbach's alpha coefficient will be calculated to assess the reliability of the tools through their internal consistency. The reliability of actual clinical learning environment inventory was 0.865 . The reliability of expected clinical learning environment inventory was 0.824 .The reliability of clinical supervision questionnaire was 0.897 . 


\section{Pilot study:}

A Pilot study was carried out on 36 nursing students from three nursing schools who represent $10 \%$ of the study subjects. The purpose of the pilot study was to test the applicability, feasibility, and objectivity of the study tools before starting data collection, and estimate the needed time to complete the questionnaire, and they were excluded from the original sample. The pilot study was conducted on two weeks, 15 to 20 minutes was the time needed to complete the questionnaires by the nursing students for each tool.

\section{Field of work}

The director of each secondary nursing school in Port Said city was informed about the purpose of the study. Once permission was granted to proceedin this proposed study all students in school who fulfilled the inclusion criteria were approached by the researcher to gain their approval to participate in the study. Then researcher started data collection by introducing herself to participants, explain to them the purpose of study and assure confidentiality. Oral consent was obtained from all students for participation in the study after explaining the aim of the study.

\section{Ethical Consideration:}

An official permission was obtained from the director of clinical area which students trainedthrough the study after explaining the purpose and the importance of the study. All participants in the study and teachers were informed about the purpose and benefits of the study and were informed that the investigator is a master candidate at the faculty of nursing, Port Said University. The researcher emphasized that participation in the study was entirely voluntary and they have the right to withdraw at any time withoutpenalty. Informed oral consent was obtained after ensuring anonymity, confidentiality and beneficence of the study data will be used only for the purpose of study.

\section{Statistical analysis:}

Data entry and statistical analysis were done using IBM SPSS software package version 20.0. (Armonk, NY: IBM Corp). Qualitative data were described using number and percent. The Kolmogorov-Smirnov test was used to verify the normality of distribution quantitative data were described using range (minimum and maximum), mean, standard deviation, significance of theobtained results was judged at $5 \%$ level. 


\section{The used tests were}

\section{1 -Wilcoxon signed ranks test}

For abnormally distributed quantitative variables, to compare between two periods, actual clinical learning environment and expected clinical learning environment.

\section{2 - Spearman coefficient}

To correlate between two distributed abnormally quantitative variables, clinical learning environment and clinical supervision.

\section{3 - Cronbach's Alpha}

Reliability Statistics was assessed using Cronbach's Alpha test. The p-value is the degree 0.05 and $\leq$ of significance. The statistical significance value was considered at $\mathrm{P}$-value 0.001. $\leq$ highly significance value at $\mathrm{P}$

\section{RESULTS:}

Table (1): showed that more than one third of participants $(41.7 \%)$ were aged $<16$ years old in first year, while one quarter of them $(25.0 \%)$ were 16-17 years in second year and (33.3\%) were $>17$ years in third year and the total students number in each school is equal (33.3\%). (24.7\%) of them were clinically trained in Port Fouad hospital. In addition, more than one quarter of students were interviewed less than three times by the nurse teacher during the course of their allocation (30.6\%), and (41.7\%) were interviewed by the nurse teacher from 4 to 6 times, lastly $(27.8 \%)$ were interviewed by nurse teacher More than 6 times.

Table (2): Show's actual clinical learning environment levels among nursing students. The highest percent of actual clinical learning environment dimensions were shown in Task orientation $(62.8 \%)$, followed by Personalization $(61.7 \%)$, and Student satisfaction (48.6\%).Whereas, most of the nursing students (80.3\%) had a low level of Involvement. While (66.4\%) of nursing student's low perception of clinical learning environment. 
Figure (1): Demonstrates levels of Actual clinical learning environment perception among nursing students. As revealed, the majority of nurse student's had a low level of actual clinical learning environment $(66.47 \%)$. While only $33.6 \%$ of them had a high level of actual clinical learning environment.

Table (3): represents expected clinical learning environment levels among nursing school students. As shown in the table, the highest percent of expected clinical learning environment dimensions were shown in Task orientation $(87.5 \%)$, followed by Student satisfaction (76.9\%), and Personalization (74.7\%). Whereas, most of the nursing school students $(39.7 \%)$ had a low perception level of Individualization in expected form. While $(76.4 \%)$ of nursing student's have high perception level of expected clinical learning environment.

Figure (2): Demonstrates levels of expected clinical learning environment among nursing school students. As revealed, the majority of nurse students had a high level of expected clinical learning environment (76.4\%). While only $(23.6 \%)$ of them had a low level of expected clinical learning environment.

Table (4): showed that Students had different perceptions about actual and expected clinical learning environments assessed by investigating the differences on related scales of the CLEI actual and expected forms. A Wilcoxon signed ranks test was used to analyze the paired samples $(\mathrm{n}=360)$. The results suggested significant differences $(\mathrm{p}<0.001)$ between all the paired scales in the actual and expected forms except individualization no significant differences $(\mathrm{p}<0.587)$.

Table (5): Represent clinical supervision levels for each dimension among nursing school students. As shown in the table, the high levels of Clinical supervision dimension were found in leadership style of ward manager, followed by Supervision relationship (36.4\%, $28.9 \%$ ) respectively. In contrast, moderate levels of Clinical supervision dimension were found in communication/ feedback (58.9\%).while, low levelof clinical supervision dimension were found in learning support assistance $(58.3 \%)$ as regard to overall percentage.

Figure (3): displays clinical supervision levels among nursing students. As shown in this figure, the majority (56.9\%) of nursing students had a moderate level of clinical supervision perception. while only, $32.8 \%$ of them was a low level of clinical supervision 
perception. Compared with $10.3 \%$ of them who had high level of clinical supervision perception.

Table (6): illustrates the correlation between clinical supervision dimensions and actual clinical learning environment dimensions among nursing School students. In light of this table, that there were a statistically significant positive correlations between all actual clinical learning environment dimensions and each of clinical supervision dimensions where $p \leq 0.05$ except between involvement with communication/feedback; Leadership style of ward manager and Learning support assistance where ranged between ( $\mathrm{r}=0.087$ to $\mathrm{r}=0.049$ ) respectively.

Table (1): Frequency distribution of nursing schools students personal characteristics $(n=360)$

\begin{tabular}{|c|c|c|}
\hline \multirow{2}{*}{ Personal characteristic items } & \multicolumn{2}{|c|}{ Nursing students } \\
\hline & No. & $\%$ \\
\hline \multicolumn{3}{|l|}{ Age } \\
\hline$<16$ years old & 150 & 41.7 \\
\hline 16-17 years old & 90 & 25.0 \\
\hline$>17$ years old & 120 & 33.3 \\
\hline \multicolumn{3}{|l|}{ Educational year } \\
\hline First year & 150 & 41.7 \\
\hline Second year & 90 & 25.0 \\
\hline Third year & 120 & 33.3 \\
\hline \multicolumn{3}{|l|}{ School name } \\
\hline Port Fouad & 120 & 33.3 \\
\hline Al Amery & 120 & 33.3 \\
\hline El Nasr & 120 & 33.3 \\
\hline \multicolumn{3}{|c|}{$\begin{array}{l}\text { Number of teachers interviewed with students in the } \\
\text { ward }\end{array}$} \\
\hline Less than 3 times & 110 & 30.6 \\
\hline From 4 to 6 times & 150 & 41.7 \\
\hline More than 6 times & 100 & 27.8 \\
\hline \multicolumn{3}{|l|}{ Clinical area name } \\
\hline Port Fouad Hospital & 89 & 24.7 \\
\hline Al Amery Hospital & 82 & 22.8 \\
\hline El Nasr Hospital & 48 & 13.3 \\
\hline Al Zohoor Hospital & 50 & 13.9 \\
\hline Obstetric Specialized Hospital & 22 & 6.1 \\
\hline Al Arab Center & 69 & 19.2 \\
\hline
\end{tabular}


Table (2): Actual clinical learning environment levels as perceived by nursing School studentsfor each dimension $(n=360)$.

\begin{tabular}{|l|c|c|c|c|}
\hline \multirow{2}{*}{ Actual clinical learning environment } & \multicolumn{3}{|c|}{ nursing School students perception } \\
\cline { 2 - 5 } & \multicolumn{2}{|c|}{ Low (<60\%) } & \multicolumn{2}{c|}{ High(>60\%) } \\
\cline { 2 - 6 } & No. & $\%$ & No. & $\%$ \\
\hline Personalization & 138 & 38.3 & 222 & 61.7 \\
\hline Student satisfaction & 185 & 51.4 & 175 & 48.6 \\
\hline Involvement & 289 & 80.3 & 71 & 19.7 \\
\hline Individualization & 222 & 61.7 & 138 & 38.3 \\
\hline Task orientation & 134 & 37.2 & 226 & 62.8 \\
\hline Innovation & 284 & 78.9 & 76 & 21.1 \\
\hline \hline Overall & 239 & 66.4 & 121 & 33.6 \\
\hline \hline
\end{tabular}

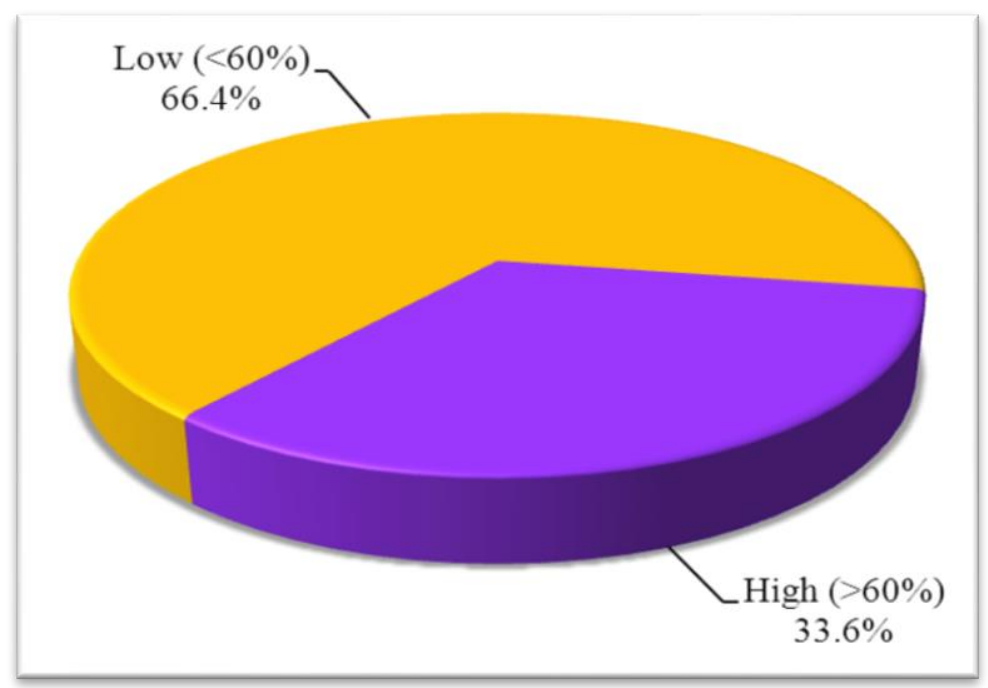

Figure (1): Actual clinical learning environment level as perceived by nursing School students $(\mathrm{n}=360)$ 
Table (3): Expected clinical learning environment levels as perceived by nursing School students for each dimension $(n=360)$.

\begin{tabular}{|c|c|c|c|c|}
\hline \multirow{3}{*}{ Expected clinical learning environment } & \multicolumn{4}{|c|}{ nursing School students perception } \\
\hline & \multicolumn{2}{|c|}{ Low $(<60 \%)$} & \multicolumn{2}{|c|}{ High $(>60 \%)$} \\
\hline & No. & $\%$ & No. & $\%$ \\
\hline Personalization & 91 & 25.3 & 269 & 74.7 \\
\hline Student satisfaction & 83 & 23.1 & 277 & 76.9 \\
\hline Involvement & 98 & 27.2 & 262 & 72.8 \\
\hline Individualization & 143 & 39.7 & 217 & 60.3 \\
\hline Task orientation & 45 & 12.5 & 315 & 87.5 \\
\hline Innovation & 106 & 29.4 & 254 & 70.6 \\
\hline Overall & 85 & 23.6 & 275 & 76.4 \\
\hline
\end{tabular}

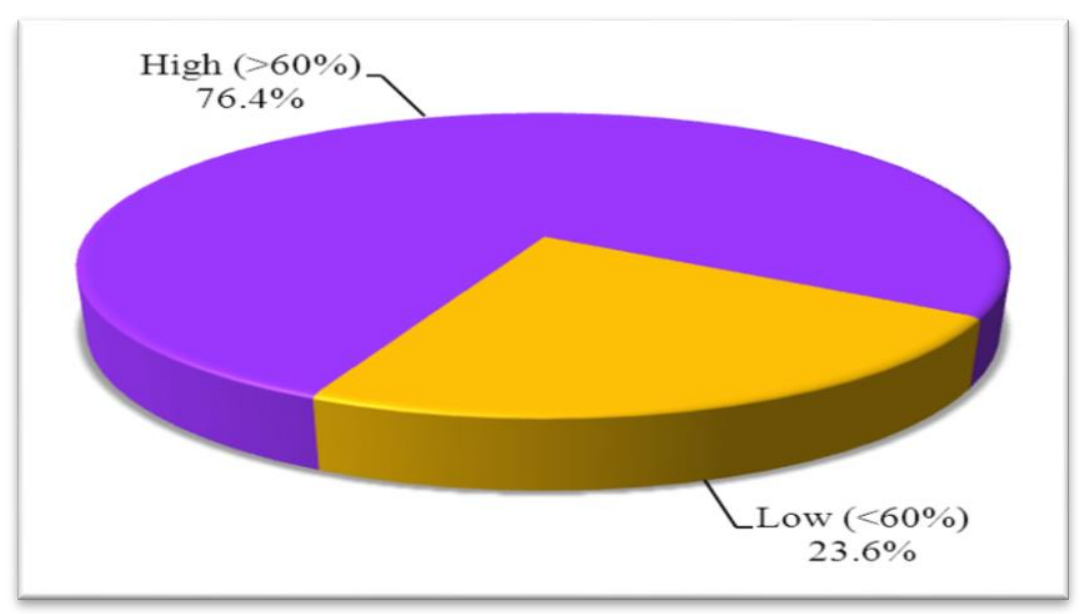

Figure (2): Expected clinical learning environment level as perceived by nursing School students $(\mathrm{n}=360)$. 
Table (4):Difference between actual and expected clinical learning environment among nursing School students at Port Said city $(\mathrm{n}=360)$.

\begin{tabular}{|c|c|c|c|c|}
\hline Clinical Learning Environment & Actual & Expected & \multirow{2}{*}{$\mathbf{Z}$} & \multirow{2}{*}{$\mathbf{P}$} \\
\hline Inventory & Mean \pm SD. & Mean \pm SD. & & \\
\hline $\begin{array}{l}\text { Personalization } \\
\text { Total score } \\
\text { percent score }\end{array}$ & $\begin{array}{c}24.17 \pm 4.66 \\
61.33 \pm 16.63\end{array}$ & $\begin{array}{c}26.95 \pm 4.90 \\
71.24 \pm 17.50\end{array}$ & $7.300^{*}$ & $<0.001^{*}$ \\
\hline $\begin{array}{l}\text { Student satisfaction } \\
\text { Total score } \\
\text { percent score }\end{array}$ & $\begin{array}{c}23.60 \pm 5.24 \\
59.29 \pm 18.73\end{array}$ & $\begin{array}{c}27.08 \pm 4.10 \\
71.72 \pm 14.64\end{array}$ & $8.707^{*}$ & $<0.001^{*}$ \\
\hline $\begin{array}{l}\text { Involvement } \\
\text { Total score } \\
\text { percent score }\end{array}$ & $\begin{array}{c}20.63 \pm 3.27 \\
48.68 \pm 11.69\end{array}$ & $\begin{array}{c}25.67 \pm 3.85 \\
66.67 \pm 13.75\end{array}$ & $13.511^{*}$ & $<0.001^{*}$ \\
\hline $\begin{array}{l}\text { Individualization } \\
\text { Total score } \\
\text { percent score }\end{array}$ & $\begin{array}{c}22.02 \pm 3.89 \\
53.63 \pm 13.89\end{array}$ & $\begin{array}{c}22.10 \pm 4.02 \\
53.94 \pm 14.34\end{array}$ & 0.544 & 0.587 \\
\hline $\begin{array}{l}\text { Task orientation } \\
\text { Total score } \\
\text { percent score }\end{array}$ & $\begin{array}{c}24.33 \pm 4.83 \\
61.87 \pm 17.24\end{array}$ & $\begin{array}{c}26.73 \pm 3.90 \\
70.45 \pm 13.92\end{array}$ & $7.346^{*}$ & $<0.001^{*}$ \\
\hline \begin{tabular}{|l} 
Innovation \\
Total score \\
percent score
\end{tabular} & $\begin{array}{c}20.44 \pm 4.05 \\
48.01 \pm 14.47\end{array}$ & $\begin{array}{c}25.49 \pm 4.19 \\
66.03 \pm 14.96\end{array}$ & $12.383^{*}$ & $<0.001^{*}$ \\
\hline $\begin{array}{l}\text { Overall } \\
\text { Total score } \\
\text { percent score }\end{array}$ & $\begin{array}{l}135.19 \pm 18.56 \\
55.47 \pm 11.05\end{array}$ & $\begin{array}{r}154.01 \pm 17.70 \\
66.67 \pm 10.54\end{array}$ & $11.427^{*}$ & $<0.001^{*}$ \\
\hline
\end{tabular}

\section{Z: Wilcoxon signed ranks test}

$\mathrm{p}$ : $\mathrm{p}$ value for comparing between actual and expected

*: Statistically significant at $\mathrm{p} \leq 0.05$ 
Table (5):Clinical supervision levels as perceived by nursing School students for each dimensions $(n=360)$

\begin{tabular}{|c|c|c|c|c|c|c|}
\hline \multirow{2}{*}{ Clinical supervision } & \multicolumn{2}{|c|}{ Low $<50 \%$} & \multicolumn{2}{|c|}{$\begin{array}{l}\text { moderate } \\
50 \%-75 \%\end{array}$} & \multicolumn{2}{|c|}{ high $>75 \%$} \\
\hline & No. & $\%$ & No. & $\%$ & No. & $\%$ \\
\hline Supervision relationship & 124 & 34.4 & 132 & 36.7 & 104 & 28.9 \\
\hline Communication/ feedback & 91 & 25.3 & 212 & 58.9 & 57 & 15.8 \\
\hline Leadership style of ward manager & 99 & 27.5 & 130 & 36.1 & 131 & 36.4 \\
\hline Learning support assistance & 210 & 58.3 & 82 & 22.8 & 68 & 18.9 \\
\hline Overall & 118 & 32.8 & 205 & 56.9 & 37 & 10.3 \\
\hline
\end{tabular}

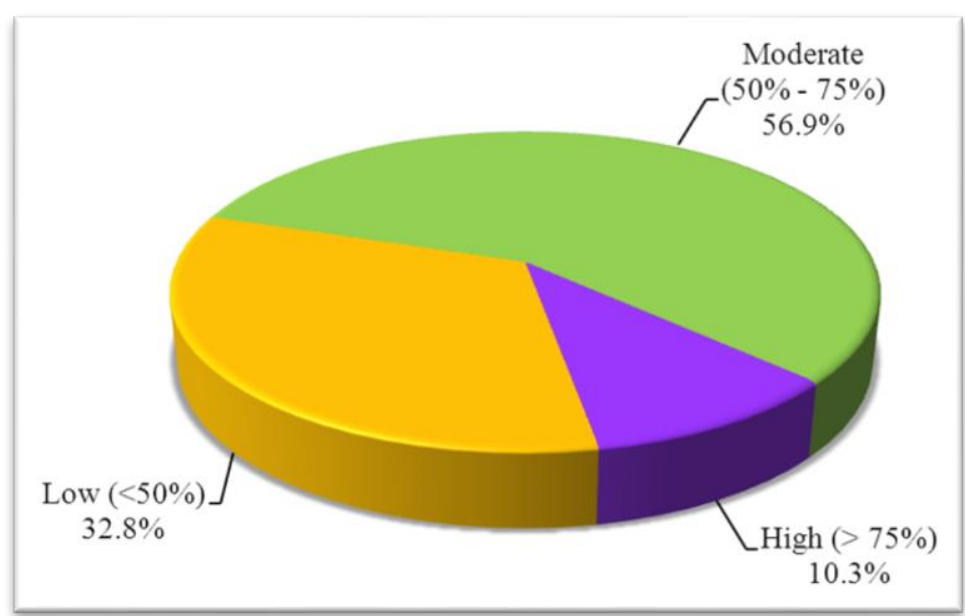

Figure (3): Clinical supervision level as perceived by nursing School students $(n=360)$ 
Table (6): Correlation between Clinical environment and their clinical supervision among nursing students $(\mathrm{n}=360)$.

\begin{tabular}{|c|c|c|c|c|c|c|}
\hline \multirow[b]{2}{*}{$\begin{array}{l}\text { Clinical Learning Environment } \\
\text { Inventory }\end{array}$} & & \multicolumn{5}{|c|}{ Tool II: Clinical Supervision Questionnaire } \\
\hline & & $\begin{array}{l}\text { Supervisor } \\
\text { relationship }\end{array}$ & $\begin{array}{c}\text { Communicat } \\
\text { ion } \\
\text { /feedback }\end{array}$ & $\begin{array}{c}\text { Leadershi } \\
\text { p style of } \\
\text { ward } \\
\text { manager }\end{array}$ & $\begin{array}{c}\text { Learning } \\
\text { support } \\
\text { assistance }\end{array}$ & Overall \\
\hline \multirow{2}{*}{ Personalization } & $\mathbf{r}_{\mathrm{s}}$ & $0.559^{*}$ & $0.372^{*}$ & $0.378^{*}$ & $0.126^{*}$ & $0.509^{*}$ \\
\hline & $\mathbf{p}$ & $<0.001^{*}$ & $<0.001^{*}$ & $<0.001^{*}$ & $0.017^{*}$ & $<0.001^{*}$ \\
\hline \multirow{2}{*}{ Student satisfaction } & $\mathbf{r}_{\mathrm{s}}$ & $0.476^{*}$ & $0.213^{*}$ & $0.281^{*}$ & $0.168^{*}$ & $0.414^{*}$ \\
\hline & $\mathbf{p}$ & $<0.001^{*}$ & $<0.001^{*}$ & $<0.001^{*}$ & $0.001^{*}$ & $0.001^{*}$ \\
\hline \multirow{2}{*}{ Involvement } & $\mathbf{r}_{\mathrm{s}}$ & $0.280^{*}$ & 0.053 & 0.087 & 0.049 & $0.188^{*}$ \\
\hline & $\mathbf{p}$ & $<0.001^{*}$ & 0.320 & 0.098 & 0.356 & $<0.001^{*}$ \\
\hline \multirow{2}{*}{ Individualization } & $\mathbf{r}_{\mathrm{s}}$ & & & & & \\
\hline & $\mathbf{p}$ & $<0.001^{*}$ & $<0.001^{*}$ & $<0.001^{*}$ & $<0.001^{*}$ & $<0.001^{*}$ \\
\hline \multirow{2}{*}{ Task orientation } & $\mathbf{r}_{\mathrm{s}}$ & & $0.145^{*}$ & $0.394^{*}$ & $0.158^{*}$ & \\
\hline & $\mathbf{p}$ & $<0.001^{*}$ & $0.006^{*}$ & $<0.001^{*}$ & $0.003^{*}$ & $<0.001^{*}$ \\
\hline \multirow{2}{*}{ Innovation } & $\mathbf{r}_{\mathrm{s}}$ & $0.380^{*}$ & $0.243^{*}$ & $0.261^{*}$ & $0.143^{*}$ & $0.374^{*}$ \\
\hline & $\mathbf{p}$ & $<0.001^{*}$ & $<0.001^{*}$ & $<0.001^{*}$ & $0.007^{*}$ & $<0.001^{*}$ \\
\hline \multirow{2}{*}{$\begin{array}{l}\text { Overall Actual Clinical Learning } \\
\text { Environment }\end{array}$} & $\mathbf{r}_{\mathrm{s}}$ & $0.657^{*}$ & $0.323^{*}$ & $0.440^{*}$ & $0.240^{*}$ & $0.605^{*}$ \\
\hline & $\mathbf{p}$ & $<0.001^{*}$ & $<0.001^{*}$ & $<0.001^{*}$ & $<0.001^{*}$ & $<0.001^{*}$ \\
\hline
\end{tabular}

$\mathrm{r}_{\mathrm{s}}$ : Spearman coefficient

$*$ : Statistically significant at $p \leq 0.05$ 


\section{DISCUSSION:}

Clinical learning environment has an important role in nursing students' learning. Any difference between actual and expected clinical environment will decrease nursing students' interest in clinical environments and has a negative correlation with their clinical performance. The perceptions and experiences of the students regarding clinical supervision provided information from the student's viewpoint, this information could assist nursing school of education to improve the system of clinical supervision (Gabieba, Mariana, Van Der Heever, \&Stellenberg, 2014).

Regarding student's perception for actual and expected CLE, the findings of the present study revealed that the majority of nurse students had low perception of actual CLE. Whilethe mostly of nursing students had high perception of expected CLE. This finding probably due to the students' expectations of clinical environment weren't satisfied and they perceived a need for improvement in all elements of their clinical experience. In contrast, students prefer a theoretical teaching environment than a clinical teaching environment that benefits from the highest level scores in all domains

This is supported by Bigdeliet al.,(2015) who studiedclinical learning environments (actual and expected) perceptions of Iran university of medical sciences nursing students and reported that the level ofactual clinical learning environment was low and the level of expected clinical learning environment was high. However, in the study by Perliand Brugnolli's (2009) on nursing students, there were findings the level ofactual clinical learning environment was high.

Concerning perception of clinical supervision among nursing student's. As indicated by the findings of the current study, more than half nursing students had a moderate perception level of clinical supervision; this finding was noted that causes effective clinical learning among nursing students is good interpersonal relationships with supervisors and feeling part of the team. In contrast, dissatisfaction or negative experiences were seen when the staff nurses supervisor did not have any interest in teaching the nursing students. Students also need to be accepted as a part of the team. This finding is in disagreement withNorfadzilah(2018) in Malaysia who showedthat the majority of the students had high perceptions of the clinical supervision. 


\section{Part (I): Results related to difference between actual and expected clinical learning environment among nursing students}

Regarding to the difference between actual and expected clinical learning environment among nursing school students, the present study pointed out according the results, the mean scores of actual and expected situations of the clinical learning environment in all domains were different except individualization domain have nosignificant differences. There was a significant difference between actual and expected environments. In this study, the highest and lowest mean scores between actual and expected environments belonged to involvement and personalization domains, respectively.

In congruence with this finding,Pour et al.(2016) confirms a significant difference between actual and expected environments. However, this result is different fromthe study by Perliand Brugnolli's (2009) on nursing student's, there were no significant differences between the score of understanding the current situation with the expected situation

From the researcher's own point of view, it could be explained that,involvement could be considered as one of the main drivers of quality teaching improvement. This finding was in the same context with previous studyconducted by Chan (2002) who clarified that students believe that after being involved in clinical activities they experience less anxiety and stress in clinical environments. This shows that if instructors facilitate involvement of students in clinical activities, there may be a room for students' expectations. Clinical staff must provide clear instructions to render safe care by students that shows the relationship between the two domains, including "students' involvement in clinical activities" and "task orientation in clinical period" in order to facilitate student involvement in ward activities.

Innovation of clinical education" was it second domain with significant difference between actual and expected environments. This finding was in the same vein with a previous study carried out by Andrea (2012) stated that critical thinking in all health care settings is a skill that develops over time and requires the conscious application of this process. Thus, it is concluded that combination of these two essential components in teaching and learning environment will increase the effectiveness of regular methods and leads to increased learning. In the study by Pakpour (2011), the lowest score in terms of 
the existing and the expected situations was in use of educational innovation in clinical training that is consistent with the results of this study emphasized that innovation has a critical importance in clinical education of nursing students, however lack of innovation and new technologies are the critical difficulties of clinical education in Iran.

Student satisfaction was the third difference seen between actual and expected environments. This means that it was not considered in clinical education environments. In Iranian study, MoattariandRamezani (2009) supported this finding and considered student satisfaction as one of the major components of the clinical education atmosphere. Chan (2007) has considered student satisfaction as education outcome and has attracted the attention of nursing authorities and policy makers to this issue.

The fourth difference between actual and expected environments was in "task orientation domain" that is due to ambiguity of students tasks in clinical settings. They perceived task orientation as an important factor that influences the outcomes of their clinical placement. The students perceived the opportunities for themselves to be directly involved with hands-on skills often controlled by clinicians and clinical teachers. It is apparent that the participants have enjoyed applying their learned skills into practice in the clinical environment. Most importantly, the compliment from clients and clinicians for a well done job were both encouraging and rewarding. This supports the findings of Hart and Rotem (1995) which suggested that students enjoy being active and having a proper level of autonomy.

Task orientation in the CLE evaluation for understanding the extent students knowthe clinical activities in the ward are clear and well-ordered. Many students perceive clinical experience as anxiety-provoking. They often, while becoming less worried in clinical environment after few encounters in ward activities. To facilitate the beginners to enthusiastically cooperate in ward activities that probably affect the clients health directly, the working ward staff are supposed to present clear detailed directions for students' safe practice. In addition, Yazdankhah et al.(2008) also indicated unclear course objectives and tasks as the most important stress inducing factors. This study showed that students need to be task-oriented in clinical educational environments.

The fifth and last difference between actual and expected settings was "personalization", in which instructors have not paid enough attention to students' personality and did not involve them in professional and clinical practice. According to, 
Chan (2007) description of personalization, from the stand point of $74.1 \%$ of students, instructor student interaction is the strength of clinical education. Other previous study that supported this current study and conducted in Iran by Rahimi(2006) state that issue and attention to the student's personality were reported as the strengths of clinical education that should be emphasized in CE. Salmaniand Amirian (2006) indicated that $78.9 \%$ of nursing students considered instructor-student interaction and students' personality at an average point. Midwifery students believe that, in most cases, barriers in clinical education are related to instructor's personality (Tarvirdi, 2004).

\section{Part (II): Results related to relations and correlation}

The current study showedthat there were a statistically significant relation between nursing student's actual clinical learning environment perception levels and their age and educational year as actual clinical learning environment perception level is higher among the nursing students who had $>17$ years old in third year. This result may be due to older students may be more motivated when they finally enter nursing education, and as a consequence, they might have a positive attitude towards clinical placement in general. Older age may also indicate more maturity which makes it easier to tackle the varied challenges in different placement settings. In relation to this results, Torunn(2013) in Norway studied the significance of demographic variables on the clinical learning environment inventory and stated that this generally higher level of positive perceptions of the learning environment in older students. While these results were compatible with Jaradeenet al.(2012) who reported that no statistical significant difference between students satisfaction with their CLE, and students age.

It was mirrored in the current study that there wasno significant relation between nursing student's expected clinical learning environment perception levels and their personal characteristics related to all dimensions. This may be due tothat the expected clinical learning environment inventory form distributed to students in school before exposure to clinical settingsand assessed the expected experience (favorable clinical experience of students in the curriculum). This result was on the same line with the study ofPour et al.(2016) who studied a view of nursing students regarding actual and expected condition of clinical environment in ShahidBeheshti University of medical sciences, Tehran and proved thatno significant differences were observed between the status quo and all aspects of the expected status of students. 
In respect to the relation between clinical supervision among nursing students and their personal characteristics; the present study revealed that there was a statistically significant relation between nursing student's clinical supervision perception levels and age /educational year. There was a nursing school students were have17 years old in third year have a moderate levels of CS and nursing students have a low perception levels of CS were have15 years old in first year. It may be due to older age may indicate more maturity which makes it easier to tackle the varied challenges in different placement settings and have more experience for clinical supervision as they undergo clinical placement repeatedly and easy to build stronger interpersonal relationships with their supervisors as they progress. This finding is similar to Musa, et al. (2017) in Egypt who found also highly statistical relation among educational years with clinical supervision.

In addition, statistically significant relation between nursing student's CS perception levels and their school name, where the nursing school students in Port Fouad and El Nasr school have a moderate perception levels of clinical supervision, but nursing students in Al Amery school have a low perception levels of clinical supervision. From the researcher's own point of view, it could be explained that is maybe due to nursing staff that choose by Port Fouad and El Nasr School educators served as positive role model for professional nursing and serving as a resource to nursing students.

Also, there was a relation between nursing student's clinical supervision perception levels and clinical area name, as the nursing school students have moderate perception level for all clinical training area except in Al Amery hospital they have low perception level. From the researcher opinion, this is due to the majority of students who are distributed in Al-Amery Hospital are young and do not have experience in dealing with supervisors, also students in Al Amery School have bad expression about clinical supervision in hospital from older student before start training. This result agree with (Chuan\& Barnett, 2012) who study student tutor and staff nurse perceptions of the CS and noted that students are less favorable towards the CS due to differences in settings between studies. While, this finding disagreement with study by Musa et al. (2017) who founded no relation for nursing students clinical supervision and clinical area name.

In referring to the correlation between clinical learning environment and clinical supervision, the present study findings clarified that there was a statistically significant positive correlation between allactual clinical learning environment dimensions and each 
ofclinical supervision dimensions except betweeninvolvementwith communication/feedback; leadership style of ward manager and learning support assistance. This may be related to that, supervision by nurse teachers or staff members plays a major role in student's opportunity to consolidate their learning, while in clinical practice a successful development of competence during the work process is significantly determined by expert supervision during clinical practice as individual preceptor-ship promotes the students development during their clinical placements and the supervisory relationships ensure continuity.

Study by Newton, Jolly, Ockerby and Cross (2012) who confirmed thatstudent satisfaction with the clinical environment can be both as a result of and influence in creative learning environment that emphasizes the importance of physical, human, interpersonal and organizational properties, mutual respect and trust among teachers and students. A positive clinical environment and a good team spirit are the most important features of a good clinical environment and when the ward staff work together and are motivated, the students may feel both supported and well supervised also feel comfortable within the working environment.

\section{CONCLUSION:}

In the light of the main study findings, it was concluded that the majority of nurse students had a low level of actual clinical learning environment. And, the majority of nursing students had high level of expected clinical learning environment. Meanwhile,more than half of nursing students had a moderate level of clinical supervision. Moreover,there was a significant difference between actual and expected clinical learning environments. Also, there was a statistically significant positive correlation between actual clinical learning environment and clinical supervision.

\section{RECOMMENDATIONS:}

According to the results of this research, considering students' expectations of clinical teaching environment that decreasing the gap between the actual and expected clinical environments. In addition, continuous studies on clinical teaching environment evaluation and their results, and to assess clinical instructors' and clinical staff opinions about the clinical teaching environment are recommended.Also continuous study for student's experience regarding clinical supervision provided information from the student's 
viewpoint this information could assist nursing school of education to improve the system of clinical supervision.

\section{REFERENCE:}

Andrea Sullivan E: Critical thinking in clinical nurse education. (2012). Application of Paul's model of critical thinking. Nurse education in practice. 12(6):322-7.

Berntsen K\& Bjørk IT.(2010). Nursing students' perceptions of the clinical learning environment in nursing homes. The Journal of nursing education.;49(1):17.

Beukes S. \& Nolte A.G,. (2013). Guidelines for value-sensitive clinical accompaniment in community health nursing. Journal of nursing management, 21(2), 304-313.

Bigdeli S, Pakpour V, Aalaa M, Shekarabi R, Sanjari M, Haghani H, et al.(2015). Clinical learning environments (actual and expected): perceptions of Iran University of Medical Sciences nursing students. Medical journal of the Islamic Republic of Iran.29:173.

Chan D. (2001). Development of an innovative tool to assess hospital learning environments. Nurse Education Today.21(8):624-31.

Chan DS. (2002). Associations between student learning outcomes from their clinical placement and their perceptions of the social climate of the clinical learning environment. International Journal of NursingStudies.39(5):517-24.

Chan DS, Ip WY. (2007). Perception of hospital learning environment: a survey of Hong Kong nursing students. Nurse Education Today. 27(7):677-84.

Chuan OL, Barnett T (2012). Student, tutor and staff nurse perceptions of the clinical learning environment. Nurse Educ. Pract. 12: 192-197.

Dutile, C., Wright, N., \& Beauchesne, M. (2011). Virtual clinical education: Going the full distance in nursing education. Newborn and Infant Nursing Reviews, 11(1), 43e48.http://dx.doi.org/10.1053/j.nainr.2010.12.008.

Gabieba Donough, Mariana, M., Van Der Heever \& E Stellenberg, (2014). Perceptions and experiences of undergraduate nursing students of clinical 
supervision.https://scholar.sun.ac.za/bitstream/handle/10019.1/86575/donough_perceptio ns_2014.pdf; sequence=2.

Hart G, Rotem A. (1995). The clinical learningenvironment: nurses' perceptions of professional development in clinical settings. Nurse Education Today. 15(1):3-10.

Henderson A \& Tyler S. (2011). Facilitating learning in clinical practice: Evaluation of a trial of a supervisor of clinical education role. Nurse educationin practice, 11(5), 288-292.

Jaradeen N, Jaradat, R., Abo Safi A., Al-Tarawneh F.: Students satisfaction with nursing program. Bahrain Medical Bulletin. 2012; 34(1): 1-6.

John P \& Wilson. (2012). "The adult learner: the definitive classic in adult education and human resource development", industrial and commercial training, pp.438439,https://doi.org/10.1108/00197851211268045

Kaphagawani, N.C. \& Useh, U. (2013). Analysis of nursing students learning experiences in clinical practice: Literature review. Studies on Ethno-Medicine, 7 (3), 181185. Retrieved from: http://www.krepublishers.com/02-Journals/S-EM/EM-07-0-000-13Web/S-EM-07-3-000-13-Abst-PDF/S-EM-07-3-181-13-293-Useh-U/S-EM-07-3-181-13293-Useh-U-Tt.pdf [Accessed on 23 June 2014].

Pour,B.M., Manoochehri, H., Hosseini, M., Habibi, H.G., Karami, M. (2016). Views of nursing students regarding actual and expected condition of clinical environment. International Journal of Pharmacy \& Technology. June-2016 | Vol. 8 | Issue No.2 | 11624-11633 Page 11625

Moattari M, Ramezani S. (2009). Nursing Students' Perspective toward Clinical Learning Environment. Iranian Journal of Medical Education. 2009;9(2)

Newton, J.M., Jolly, B.C., Ockerby, C.M. \& Cross, W.M. (2012). Student centredness in clinical learning: the influence of the clinical teacher. Journal ofadvanced nursing, 68(10), 2331-2340.

Norfadzilah , A. (2018). Nursing Students and Clinical Instructors' Perceptions of Clinical Learning Environments, Supervision, and Teaching (CLES-T). International Journal of Care Scholars, 1(1), 11-12. 
Pakpoor W, Mehrdad N, Shekarabi R, Salimi S.(2011). Nursing Students' Perceptions Regarding Their Educational Environment of Tehran University of Medical Sciences. Journal of Medical EducationDevelopment. 3(5):16-

Perli S, Brugnolli. (2009). Italian nursing students' perception of their clinical learning environment as measured with the CLEI tool. Nurse Education Today 29(8):886-90.

Polit D.F. \& Beck C.T. (2008). Nursing Research: Generating and Assessing Evidence for Nursing Practice, 8th edn. Lippincott Williams \& Wilkins, Philadelphia.

Rahimi A, Ahmadi. (2006). The obstacles and improving strategies of clinical education from the viewpoints of clinical instractures in Tehran's Nursing Schools. Iranian Journal of Medical Education. 5(2):73-9.

Salmani N, Amirian. (2006). Comparison of attitudes of students and nursing educators, Islamic Azad University of Yazd on the situation of clinical education environment. Journal of Medical Education DevelopmentCenter. 3(1):11-8.

Shahi M , Bakhshi M \& Hassan G . (2015). Students' perceptions of the academic learning environment in seven medical sciences courses based on dreem. Adv Med Educ Pract. 23;6:195-203.

Skaalvik, M. W., Normann, H. K., \& Henriksen, N. (2011). Clinical learning environment and supervision: experiences of Norwegian nursing students-aquestionnaire survey. Journal of clinical nursing, 20(15-16), 2294-2304

Tarvirdi M.(2004). Factors in the quality of clinical education of midwifery students and teachers and to determine factors associated with these features coaches in Tabriz Faculty of Nursing and Midwifery. Proceedings of the National Conference on Education in Nursing and Midwifery Zanjan. p. 19.

YazdankhahFard M, Pouladi, Kmali, Zahmatkeshan, Mirzaie, Akaberian, et al.(2008). The Stressing Factors in Clinical Education: The Viewpoint of Students. Iranian Journal of Medical Education. 8(2):341-9. 
